\title{
AKTUALISASI WANITA BERPENDIDIKAN PADA ERA GLOBALISASI DALAM MENJAGA ETIKA DAN MORAL LINGKUNGAN
}

\author{
Anna Fitri Hindriana, Yeyen Suryani, Lilis Lismaya \\ Universitas Kuningan, Indonesia. \\ E-mail : anna@uniku.ac.id
}

\begin{abstract}
The development of moral and environtmental ethics must be started early. This is because someone's success is deeply affected by their characther that has been nurtured since childhood. 0 - 5 years old is the period when the children are capable to do information accomodation processing from their suroundding very quicky, thus the ealy years of children is an opportunity to give them understanding about proper ethics and environtmental moral. The nurture of ethics and environtmental moral is not only the obligation of the teacher but also parents. In accordance with that, the aim of this community service is to 1) give understanding to parents about the necessity of sinergy between parents and pre-school teachers for children's ethics and environtmental moral development, 2) enhance pre-school teachers' and parents' understanding about the principals that need to be applied in developing ethics and evinrontmental moral. The method used in this activity were 1) Training for pre-school teacher and parents on early childhood ethics and moral development, 2) assistance in creating ethics and moral based lesson plan for pre-school teachers. The result that attained is the improvement of pre-school teachers' and parents' understanding on ethics and moral and the improvement of ethics and moral based lesson plan quality.
\end{abstract}

Keywords: Ethics, moral, environtment, early childhood

\begin{abstract}
Abstrak
Indonesia tengah mengalami proses kehilangan, mulai kehilangan aspek fisik, alam hayati, manusia dan budaya. Wanita mampu berperan baik di bidang pendidikan dan domestik sebagai pendidik pertama dan utama yang harus mengambil langkah-langkah strategis untuk menyelamatkan generasi bangsa. Pengembangan moral dan etika lingkungan harus dimulai sejak dini, hal ini dikarenakan keberhasilan dan kesuksesan seseorang sangat dipengaruhi oleh karakter yang terbangun semenjak kecil, usia 0 sampai 5 tahun yang merupakan masa dimana anak melakukan proses akomodasi informasi dari lingkungan yang sangat cepat oleh karena itu pada masa-masa awal pertumbuhan merupakan kesempatan diberikannya pemahaman tentang etika dan moral lingkungan yang baik. Pembentukan moral dan etika lingkungan bukan hanya merupakan tanggung jawab guru tetapi harus bersinergi dengan orang tua di rumah. Tujuan dari pengabdian masyarakat ini untuk : 1) memberikan pemahaman pentingnya sinergi pengembangan etika dan moral lingkungan pada anak oleh guru PAUD dan orang tua, 2) meningkatkan pemahaman guru PAUD dan orang tua tentang prinsip-pinsip yang harus dikembangkan dalam mengembangkan etika dan moral lingkungan. Metode yang digunakan dalam kegiatan ini; 1) pelatihan kepada orang tua dan guru PAUD tentang progam pengembangan etika dan moral lingkungan anak usia dini, 2) pendampingan pembuatan rancangan pembelajaran berbasis etika dan moral bagi guru-guru PAUD. Hasil yang dicapai adalah peningkatan pemahaman orang tua dan guru-guru PAUD tentang etika dan moral lingkungan dan peningkatan kualitas rancangan pembelajaran berbasis etika dan moral lingkungan.
\end{abstract}

Kata Kunci : Etika, Moral, Lingkungan, Anak Usia Dini

\section{PENDAHULUAN}

Perempuan merupakan sebuah titik tolak maju tidaknya suatu bangsa, perempuan dapat dikatakan sebagai tiang negara, karena mereka merupakan pendidik pertama dan utama bagi anak-anaknya, serta pendamping yang selalu mendukung bagi pasangannya. Perempuan masa kini sudah sepatutnya berperan serta dalam menata moral dan memiliki dedikasi tinggi serta mempunyai orientasi untuk mendidik generasi - generasi penerusnya. Tantangan perempuan masa kini tak hanya lagi pendidikan bagi 
perempuan, kaum perempuan saat ini sudah diberikan kesempatan yang sama untuk menempuh bidang pendidikan dalam semua jenjang, namun perjuangan perempuan masa kini lebih mengarah pada pendidikan yang menyelamatkan generasi muda Indonesia. Tentu ini merupakan tantangan yang sangat besar bagi kaum perempuan apapun pekerjaannya dan setinggi apapun jenjang pendidikannya, karena sudah kodratnya kaum perempuan merupakan pendidik pertama dan utama bagi anakanaknya.

Marilah kita sejenak melihat lingkungan tempat kita tinggal, apakah lingkungan tempat kita tinggal sudah terjaga moral dan etikanya? Perubahan apa yang kita rasakan dan bagaimana dampaknya terhadap generasi yang akan datang?. Apabila kita cermati maka banyak perubahan yang terjadi pada lingkungan kita, berbagai gejolak dalam masyarakat kita pada beberapa tahun terakhir ini yang sangat memprihatinkan kita semua. Pertama, munculnya karakter buruk yang ditandai kondisi kehidupan sosial budaya kita yang berubah sedemikian drastis dan fantastis. Bangsa yang sebelumnya dikenal penyabar, ramah, penuh sopan santun dan pandai berbasa-basi sekonyongkonyong menjadi pemarah, suka mencaci, pendendam. Kedua dalam tiga dekade terakhir ini Indonesia tengah mengalami proses kehilangan, mulai kehilangan aspek fisik, alam hayati, manusia dan budaya. Aspek fisik kita telah banyak kehilangan tanah subur, dan berganti dengan bertambahnya lahan kritis (Departemen Kehutanan), kehilangan aspek alam hayati, kita telah kehilangan hutan tropis dengan laju deforestasi tertinggi di dunia. Dalam aspek manusia, Indonesia kehilangan daya saing, kehilangan niat untuk mentaati hukum, bahkan mentaati aturan yang paling sederhana yaitu aturan berlalu lintas (Cris Haryanto dan Rahmani, 2017). Dalam aspek budaya kita kehilangan kecintaan terhadap kesenian tradisional sebagai warisan budaya, sebagian dari kita sudah kehilangan rasa malu dan kejujuran. Hal-hal tersebut di atas merupakan ciri adanya masalah dalam etika dan moral di masyarakat yang disebabkan pendidikan kurang menekankan pada pengembangan karakter (Lickona, 1991);(Nurkamilah,2018). Namun apakah kita harus menyerah dengan keadaan ini? Bagaimana upaya kita sebagai kaum perempuan untuk tetap bisa menyelamatkan generasi yang akan datang?.

Sebuah kondisi nilai sosial masyarakat dan budaya Indonesia, dewasa ini telah menjadi semakin terabaikan. Sementara, budaya luar telah menjamur masuk dalam kehidupan generasi masa kini, khususnya masyarakat Indonesia. Generasi muda Tanah Air kian terlena dengan aneka sajian informasi yang serba mudah dan instan ini serta melupakan jati diri yang sebenarnya, sebuah jati diri bangsa yang sedikit demi sedikit mulai luntur (Tanyid, 2014). Kegalauan yang menyelimuti kaum muda Indonesia membuat mereka menelan mentah-mentah budaya bangsa lain dan mengadopsinya seakan itu adalah budaya sendiri. Arus informasi yang kian pesat tentu harus disikapi secara bijak, harus kita akui tidak semua informasi yang ada itu menyesatkan. Kita harus mampu memfilter informasi tersebut agar menjadi informasi yang bermanfaat. Sebagai kaum perempuan kitalah yang menjadi alat filter informasi tersebut untuk generasi penerus, kita harus memiliki kemampuan yang baik dalam hal mengolah informasi, dan menggunakan alat informasi tersebut. Dengan demikian kita harus 
menjadi kaum perempuan terdidik yang tetap mengedepankan hati nurani. Meningkatkan kualitas pendidikan melalui berbagai inovasi serta manajeman merupakan tugas semua pihak (Nurcahyono, Sutisnawati dan Nurasiah. 2019).

Desa Cisantana merupakan salah satu desa di kabupaten Kuningan yang termsuk desa wisata yang banyak dikunjungi oleh wisatawan. Kehadiran wisatawan memang sangat mempengaruhi kesejahteraan penduduk di daerah tersebut, namun ada dampak yang lainnya yaitu budaya yang dibawa oleh para wisatawan tersebut dapat mempengaruhi lingkungan sosial budaya, lingkungan ekonomi, lingkungan alam setempat. Oleh karena itu perlu adanya peranan kaum wanita dalam mensosialisakan etika dan moral lingkungan pada anak-anak sejak usia dini dan ke lingkungan masyarakat terutama peranan ibu-ibu penggerak PKK dan guru-guru PAUD. Dengan diberikannya pengetahuan tentang etika dan moral lingkungan mulai dari usia dini diharapkan akan mampu menumbuhkembangkan kemampuan dasar anak-anak agar berpikir cerdas, berperilaku yang berakhlak, bermoral, dan berbuat sesuatu yang baik, yang bermanfaat bagi diri sendiri, keluarga dan masyarakat.

\section{METODE PELAKSANAAN}

Alur kegiatan pengabdian masyarakat pengembangan etika dan moral lingkungan di desa Cisantana Kabupaten Kuningan adalah sebagai berikut;

1. Pengembangan etika dan moral lingkungan melalui pelatihan guru-guru PAUD dalam menjaga nilai-nilai etika dan moral lingkungan dalam pembelajaran .

2. Pengembangan etika dan moral lingkungan pada keluarga dan masyarakat melalui pelatihan ibu-ibu penggerak PKK dalam mensosialisasikan etika dan moral lingkungan

3. Pengembangan RPP berbasis etika dan moral lingkungan melalui pendampingan guru-guru PAUD dalam mengimplementasikan etika dan moral lingkungan dalam membentuk kepribadian siswa untuk dapat mengimplementasikan di lingkungan rumah, dan lingkungan masyarakat

4. Mengukur kesadaran ibu-ibu penggerak PKK dalam mengimplementasikan etika dan moral lingkungan pada keluarga dan masyarakat.

\section{HASIL DAN PEMBAHASAN}

Pelatihan pengabdian kepada masyarakat ini dapat berjalan dengan baik. Pelatihan dapat terlaksana pada tanggal 20-22 Agustus 2019 dengan jumlah peserta sebanyak 37 peserta yang berasal dari 10 orang guru PAUD dan 27 ibu-ibu Penggerak PKK Desa Cisantana. Secara keseluruhan pelaksanaan pelatihan ini cukup berhasil. Berdasarkan analisis RPP yang dibuat oleh guru - guru PAUD, wawancara, tanya jawab dan pengamatan langsung selama kegiatan berlangsung, kegiatan pengabdian pada masyarakat ini memberikan hasil sebagai berikut:

1. Menambah pengetahuan guru - guru PAUD dalam mengembangkan etika dan moral lingkungan dalam proses pembelajaran yang tertuang pada RPP 
2. Meningkatkan kesadaran dan kreativitas guru dalam mengembangkan etika dan moral lingkungan yang berhubungan dengan kehidupan sehari-hari.

3. Membantu meningkatan kompetensi guru dalam membuat RPP yang menekankan pada pengembangan sikap peserta didik berdasarkan nilai-nilai dalam menjaga etika dan moral lingkungan.

4. Membantu peran ibu-ibu penggerak PKK dalam mengimplementasikan etika dan moral di lingkungan keluarga dan masyarakat.

5. Memberikan wawasan terhadap ibu-ibu penggerak PKK tentang etika dan moral lingkungan yang harus ditanamkan secara berkelanjutan sebagai bagian dari pendidikan kepribadian anak yang telah ditanamkan di sekolah.

Hasil pengabdian kepada masyarakat menunjukkan keberhasilan yang cukup memuaskan. Hal ini terlihat dalam tahapan pelaksanaan kegiatan yang dimulai tahap pemberian materi, diskusi, dan praktek terbimbing peserta terlihat antusias. Respon guru-guru PAUD dan ibu-ibu penggerak PKK cukup baik terlihat dari pertanyaanpertanyaan yang diajukan pada pelatih. Pada pelatihan ini dapat dievaluasi bahwa sebagian besar peserta ibu-ibu Penggerak PKK belum mengetahui etika dan lingkungan yang harus diimplementasikan di masyarakat dan bagaimana memberikan kesadaran kepada masyarakat dalam menerapkan etika dan moral lingkungan, hal ini dikarenakan adanya rasa canggung untuk menegur atau memperbaiki etika dan moral orang lain. Begitu pula guru-guru PAUD masih kesulitan dalam mengembangkan etika dan moral dalam pembelajaran terlebih mereka merasa kesulitan apabila harus menuangkannya dalam RPP, hal ini dikarenakan hanya 2 (dua) dari 10 guru PAUD yang berlatar belakang sarjana pendidikan. Melalui pelatihan ini peserta mempelajari teknik-teknik dalam mengembangkan penerapan etika dan lingkungan baik di dalam dunia pendidikan maupun di lingkungan keluarga maupun masyrakat melalui serangkaian teknik yang mengembangkan proses afektif yang bersifat kontekstual. Kemampuan peserta terutama guru-guru PAUD di akhir tahap pelaksanaan yaitu pada tahap praktek terbimbing cukup baik, dengan pemberian teknik-teknik yang tepat di awal tahap pelaksanaan peserta sudah dapat menerapkan teknik-teknik yang benar dalam mengimplementasikan etika dan lingkungan dalam pembelajaran dan dituangkan dalam RPP.

Berdasarkan hasil wawancara dengan 10 orang guru PAUD dalam sesungguhnya mereka telah mengimplementasikan etika dan moral lingkungan pada pembelajaran di PAUD melalui pelaksanaan karyawisata di daerah Cisantana dan metode dongeng yang berkaitan dengan etika dan moral di lingkungan keluarga dan masyarakat, namun mereka belum menuangkan secara terencana dalam bentuk RPP. Proses pendampingan meliputi pengembagan pendekatan pembelajaran, strategi yang digunakan untuk mencapai tujuan pembelajaran yaitu tertanamnya etika dan moral lingkungan dalam pribadi siswa, metode yang efektif dalam menanamkan nilai-nilai yang terkandung dalam etika dan moral lingkungan serta pengembangan RPP. Hasil dari pendampingan pengembangan RPP peserta dapat merencanakan pembelajaran yang lebih terstruktur mulai dari apersepsi, motivasi terhadap siswa dengan 
menampilkan suatu fenomena tentang implementasi etika dan moral lingkungan yang kontekstual melalui dongeng, selanjutnya guru mengintegrasikan pengetahuan tentang etika dan moral pada tema yang sedang diajarkan, sehingga diharapkan dengan mengintegrasikan etika dan moral lingkungan terhadap setiap materi yang sedang diajarkan akan menumbuhkan kesadaran sejak usia dini untuk mengimplementasikan dalam lingkungan keluarga maupun lingkungan masyarakat.
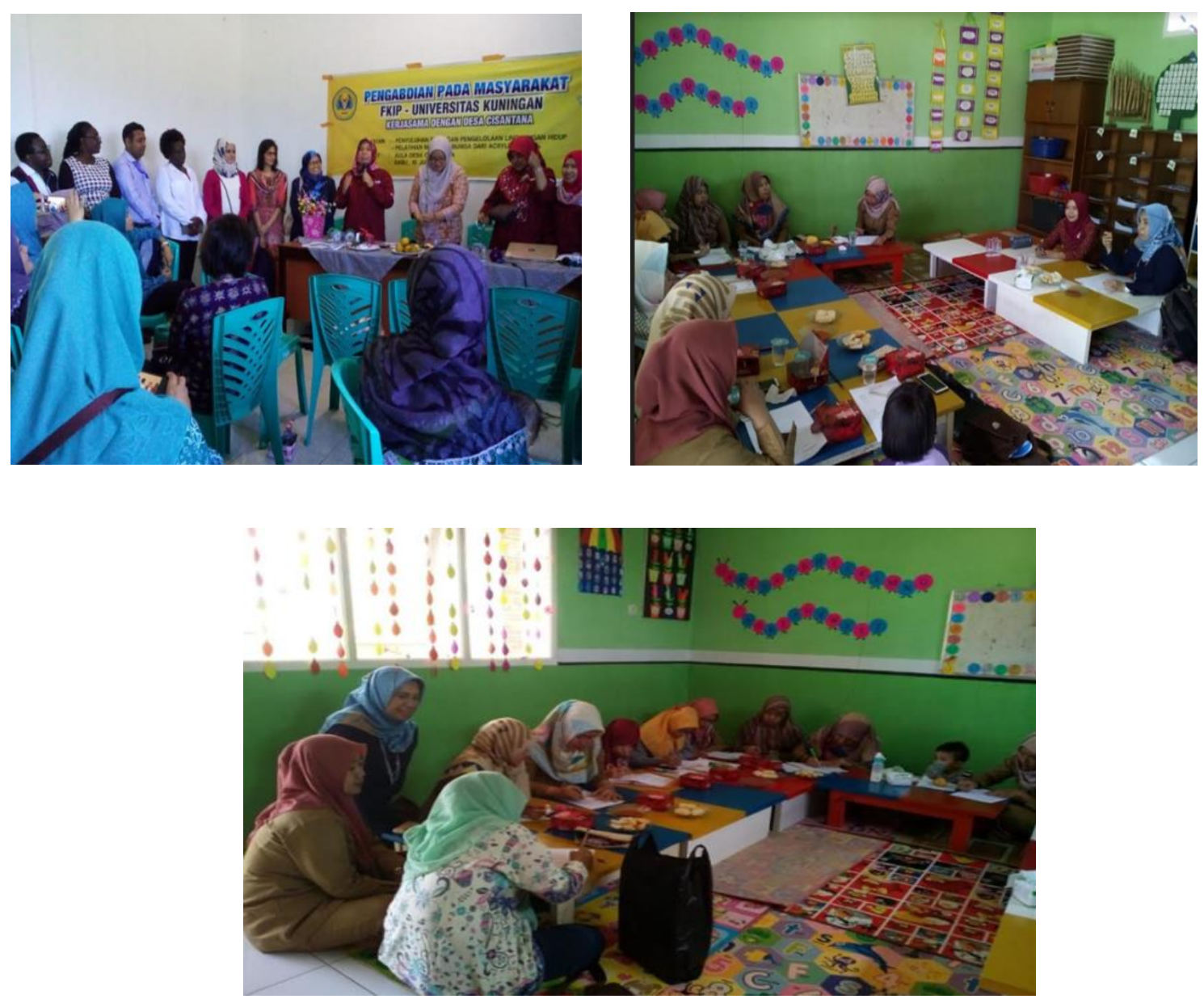

Gambar. Kegiatan Pelatihan dan Pendampingan Etika dan Moral Lingkungan bagi Ibu- ibu Penggerak PKK dan Guru PAUD di Desa Cisantana

Bagi ibu-ibu penggerak PKK lebih memiliki kepercayaan diri dalam mengimplementasikan nilai-nilai karakter di lingkungan keluarga secara berkelanjutan, namun untuk mengimplementasikan ke lingkungan masyarakat mereka akan berupaya melalui pengajian yang rutin dilaksanakan di setiap RT maupun di desa. Hal ini untuk menghindari kecanggungan apabila di lingkungan masyarakat ada perilaku yang tidak sesuai dengan etika dan moral lingkungan yang dikembangkan.

Sebagian besar ibu-ibu PKK untuk menanamkan etika dan moral lingkungan dikaitkan dengan agama, hal ini dikarenakan anak-anak mereka mengikuti pendidikan 
agama di Taman Pendidikan Al Qur'an, berdasarkan angket yang disebarkan peserta menyatakan akan menindaklanjuti pengetahuan etika dan moral lingkungan yang telah didapatkan anak-anak baik dari TPA maupun sekolah. Untuk menjaga lingkungan alam peserta menyatakan akan memanfaatkan sampah rumah tangga untuk membuat pupuk organik dan menjaga kelestarian alam dengan memelihara lingkungan sekitar dan mengadakan gotong royong dalam menjaga lingkungan agar tetap bersih dan nyaman

Mengingat keterampilan guru-guru PAUD tentang pengembangan RPP masih belum cukup diperlukan kegiatan pelatihan semacam ini di masa mendatang dengan materi yang lebih beragam. Hal ini bertujuan untuk memberikan pengetahuan beragam kepada peserta mengenai teknik-teknik pengembangan pembelajaran untuk meningkatkan kemampuan siswa dalam ranah afektif begitu juga perlu adanya pelatihan tentang peranan wanita dalam mengaktualisasikan dirinya agar dapat lebih percaya diri dalam mendidik anaknya di lingkungan keluarga maupun memberikan konrtibusi nyata dalam membangun masyarakat terutama pada nilai-nilai afektif yang berkembang di masyarakat. Sejalan dengan usulan peserta pelatihan pengabdian kepada masyarakat yang mengharapkan kegiatan sejenis di masa mendatang dengan tema atau materi yang berbeda.

Faktor yang mendukung terlaksananya kegiatan pelatihan pengabdian kepada masyarakat ini adalah besarnya minat dan antusiasme peserta selama kegiatan, sehingga kegiatan berlangsung dengan lancar dan efektif. Kepuasan peserta ditunjukkan dalam hasil angket yang diberikan setelah pelaksanaan pelatihan dan pendampingan yang menunjukkan sebagian besar peserta merasa puas dengan pelatihan dan pendampingan yang dilaksanakan. Peserta juga menyatakan bahwa materi pelatihan yang diberikan dapat membantu menambah pengetahuan terkait penerapan karakter baik di lingkungan pendidikan anak usia dini, lingkungan keluarga maupun lingkungn masyarakat di Desa Cisantana. Faktor yang dianggap dapat menghambat adalah keterbatasan waktu pelatihan dan ketersediaan waktu peserta yang penuh dengan kegiatan lainnya terutama bagi ibu-ibu penggerak PKK yang sebagian besar adalah ibu rumah tangga yang masih memiliki anak usia PAUD - SD.

\section{SIMPULAN}

Berdasarkan uraian kegiatan pengabdian pada masyarakat ini maka dapat disimpulkan bahwa:

1. Pengetahuan dan pemahaman guru - guru PAUD mengenai kegiatan pengembangan moral dan etika lingkungan dalam pembelajaran lebih meningkat terutama dalam mengembangkan moral dan etika siswa yang bersifat kontekstual dan memberikan contoh yang lebih komprehensif.

2. Kemampuan guru-guru PAUD dalam mengembangkan pembelajaran berbasis etika dan moral lingkungan dalam RPP lebih baik dari sebelumnya.

3. Kesadaran ibu-ibu penggerak PKK dalam mempelajari dan mengimplementasikan etika dan moral lingkungan di lingkungan keluarga dan masyarakat menjadi meningkat. 


\section{SARAN}

Mengingat besarnya manfaat kegiatan pengabdian pada masyarakat ini, maka selanjutnya perlu:

1. Peran perguruan tinggi (dosen) sangat diperlukan untuk meningkatkan kompetensi guru-guru PAUD dan masyarakat pada umumnya dalam pengembangan etika dan moral lingkungan dalam mendukung penerapan nilai-nilai karakter yang telah ditentukan oleh pemerintah dalam rangka mewujudkan tujuan Pendidikan Nasional.

2. Mengadakan bentuk pelatihan sejenis dengan materi yang lebih beragam

3. Mengadakan pelatihan serupa pada khalayak sasaran yang berbeda serta wilayah jangkauan yang lebih luas.

4. Adanya kesinambungan dan monitoring program pasca kegiatan pengabdian ini sehingga guru-guru PAUD dan masyarakat teruta ibu-ibu penggerak PKK benarbenar dapat mengembangkan etika dan moral lingkungan di lingkungan sekolah, keluarga dan masyarakat di daerahnya masing-masing.

\section{UCAPAN TERIMA KASIH}

Penulis ucapkan terima kasih kepada LPPM Universitas Kuningan, Rektor Universitas Kuningan, Pemerintah Daerah Kabupaten Kuningan serta masyarakat dan pihak lainnya atas segala dukungan yang telah diberikan sehingga terselenggaranya kegiatan pengabdian ini.

\section{DAFTAR PUSTAKA}

Chris Haryanto.H, Rahmani.T, (2017), Nilai-Nilai Yang Penting Terkait Dengan Etika, Jurnal Psikologi Ulayat, 4 (1), Halaman. 1-10

Lickona, Thomas. (1991), Educating for Character: How Our School Can Teach Respect and Responsibility, New York, Toronto, London, Sydney, Aucland: Bantam Books.

Novi Andri Nurcahyono, Astri Sutisnawati dan Iis Nurasiah. 2019. Lokakarya Manajemen Berbasis Sekolah (MBS) dan Implementasi Pada Kurikulum 2013

Di Sekolah Dasar (SD) Di Sukabumi, Indonesia. Empowerment : Jurnal Pengabdian Masyarakat, e-ISSN 2598-2052 Vol. 02 Nomor 01. 2019.11-17

Nurkamilah, C., (2018), Etika Lingkungan Dan Implementasinya Dalam Pemeliharaan Lingkungan Alam Pada Masyarakat Kampung Naga, Jurnal Studi Agamaagama dan Lintas Budaya 2, (2), Halaman 136-148

Tanyid, M., (2014). Etika Dalam Pendidikan: Kajian Etis Tentang Krisis Moral Berdampak Pada Pendidikan, Jurnal Jaffray, 12 (2), Halaman 235-250. 